\title{
Why Ectogestation Is Unlikely to Transform the Abortion Debate: a Discussion of 'Ectogestation and the Problem of Abortion'
}

\section{Daniel Rodger ${ }^{1}$ (D)}

Received: 9 October 2020 / Accepted: 22 October 2020 / Published online: 2 November 2020

(C) The Author(s) 2020

\begin{abstract}
In this commentary, I will consider the implications of the argument made by Christopher Stratman (2020) in 'Ectogestation and the Problem of Abortion'. Clearly, the possibility of ectogestation will have some effect on the ethical debate on abortion. However, I have become increasingly sceptical that the possibility of ectogestation will transform the problem of abortion. Here, I outline some of my reasons to justify this scepticism. First, I argue that virtually everything we already know about unintended pregnancies, abortion and adoption does not prima facie support the assumption that a large shift to ectogestation would occur. Moreover, if ectogestation does not lead to significant restrictions to abortion, then there will be no radical transformation of the practice of abortion. Second, abortion is already associated with stigma, and so the presence of ectogestation would need to create additional stigma to modify behaviour. Finally, I argue that ectogestation shifts the debate away from the foetus to the human subject of the artificial womb - the gestateling, therefore creating a new category of killing - gestaticide. However, this would only reorient the debate rather than end it.
\end{abstract}

Keywords Abortion · Pregnancy · Infanticide · Gestation · Ectogestation · Adoption

\section{Introduction}

Christopher Stratman (2020) defends the claim that there is no right to the death of the foetus when ectogestation is possible, even if they lack the moral status of a person.

Daniel Rodger

daniel.rodger@1sbu.ac.uk

1 School of Health and Social Care, London South Bank University, 103 Borough Rd., London SE1 OAA, UK 
This is a conclusion I have argued for previously (Blackshaw and Rodger 2019) in response to those who have argued to the contrary (Räsänen 2017). ${ }^{1}$ Though there are many arguments against the claim that there is a right to the death of the foetus, it seems unlikely that the possibility of ectogestation will radically transform the abortion debate - especially that it will cause a reduction in the incidence of abortion.

Here, I briefly outline some challenges against Stratman's (2020) claim that the possibility of ectogestation - a period of gestation in an artificial ex utero environment - will radically transform the problem of abortion. First, I argue that virtually everything we already know about unintended pregnancies, abortion and adoption seems to suggest that a large shift to ectogestation is unlikely to occur. Moreover, if ectogestation does not lead to significant legal restrictions on abortion, then there is unlikely to be any radical transformation on the practice of abortion. Second, abortion is already associated with stigma, and so the presence of ectogestation would need to increase the existing stigma to modify behaviour away from abortion. Finally, I argue that artificial womb technology shifts the debate away from the foetus to the human subject of the artificial womb - what Elizabeth Chloe Romanis (2018) has termed the gestateling. It creates a new category of killing - gestaticide - which will more closely resemble the ethical debate around infanticide rather than abortion (Rodger et al. 2020).

\section{Adoption, Harm and Stigma}

Women who have an unintended pregnancy can already entrust the moral and legal responsibilities of parenthood to a competent individual or couple — via adoption. In many ways, ectogestation allows for the same opportunities as adoption. In both cases, the resulting gestatelings' or neonates' needs are met by something or someone else. Moreover, both provide a means for continued human existence, in contrast with induced abortion. One obvious difference is that in the case of ectogestation, the period of gestation would be less than completing a normal pregnancy (e.g. perhaps they could be transferred to an artificial womb at 24 weeks); otherwise, there would be little reason to opt for ectogestation over adoption in the case of an unintended pregnancy.

Women with an unintended pregnancy are the group most likely to have an abortion, with $61 \%$ of unintended pregnancies between 2015 and 2019 ending in abortion (Bearak et al. 2020); globally, 25\% of pregnancies end in abortion (Sedgh et al. 2016). Therefore, ectogestation would need to be employed very early on in the pregnancy-because women who would otherwise seek an abortion will likely not want to be delayed in relieving the burdens they perceive or associate with their pregnancy. In most high-income countries, at least $90 \%$ of induced abortions are completed before the 13th week of pregnancy (Popinchalk and Sedgh 2019). Most women who consider abortion do not choose to complete the pregnancy and give their child up for adoption (Sisson et al. 2017). Unless it is medically indicated, women do not and are not legally permitted to request to deliver their foetus prematurely at the point of viability (24-28 weeks) with the intent that the child receive neonatal intensive care under the responsibility of adoptive parents. If ectogestation is to function as an alternative to abortion, this is what women would be expected to do. However, based

\footnotetext{
${ }^{1}$ As have many others, see Mathison and Davis (2017), Hendricks (2018), and Kaczor (2018).
} 
on what is already known about women who consider and procure abortions, ectogestation would need to be available at a much earlier stage of pregnancy than the point of viability. ${ }^{2}$

The reasons for not opting for foetal transfer surgery, ectogestation and adoption are likely to be similar or the same as those given for not completing the pregnancy and giving the child up for adoption. In fact, there are additional reasons for women to object to this process - the need for invasive surgery to transfer the foetus into an artificial womb despite the fact that abortion obtained early in pregnancy is relatively safe for women (National Institute for Health and Care Excellence 2019).

The invasive surgery required for a foetal transfer is likely to be analogous to the surgery required for a caesarean section, and therefore, the risks involved will be closely aligned. Given that the vast majority of induced abortions occur before the 13th week of pregnancy, the overall risks (e.g. rates of serious complications) are likely to be lower - where abortion is legal - than those that would be associated with foetal transfer surgery, if they reflect the risks associated with caesarean section. ${ }^{3}$ This in itself is not an argument for abortion; otherwise, the increased complication risks associated with naturally giving birth compared with early abortion could be used to argue that abortion would be clinically indicated for all pregnancies. ${ }^{4}$ This point merely shows that the increased risks that would be associated with foetal transfer surgery, when compared with the comparatively lower risks of early induced abortion, are likely to reinforce the decision to opt for abortion and not ectogestation.

In a study of women in the USA who had abortions, the reason they gave for not giving their child up for adoption was that giving up one's child was considered morally unconscionable (Finer et al. 2005). This is congruent with the existing research that explores women's views of ectogestation compared with abortion (Cannold 1995; Simonstein and Mashiach-Eizenberg 2009). In a qualitative study by Leslie Cannold (1995, p.60), adoption (and ectogestation) was understood by some women as an 'irresponsible abdication...of their maternal responsibilities'. Furthermore, the use of ectogestation for resolving an unintended pregnancy was viewed negatively by women irrespective of their views on abortion, even when ectogestation was described as no more medically risky or inconvenient than abortion (Cannold 1995). This means that even if there is no right to the death of the foetus, the possibility of ectogestation is unlikely to affect women's decision-making if adoption is perceived as being psychologically distressing (Jones et al. 2008).

The primary reason that we would expect women to opt for ectogestation would be if legal restrictions were implemented against abortion based on the presence of artificial womb technologies. This is of course theoretically possible but improbable - especially in countries where legal abortion is not connected to foetal viability. It would require a significant shift in the current cultural and international trajectory of abortion legislation. This trajectory is evidenced by the trend towards decriminalising abortion, most recently in Northern Ireland in 2019 (Aiken and Bloomer 2019), and expanding the legally permitted grounds for abortion (Guillaume and Rossier 2018). In other words,

\footnotetext{
${ }^{2}$ Realistically, ectogestation would need to be available prior to 13 weeks to act as an alternative to abortion.

${ }^{3}$ For a discussion of a similar point and an argument for why ectogestation should not be considered as an alternative to pregnancy or abortion, see Romanis et al. (2020).

${ }^{4}$ For a discussion of this point, see Blackshaw and Rodger (2020).
} 
international trends appear to be moving towards broadening abortion access, not restricting it in ways that would be required were ectogestation to become available.

A central question, therefore, is this: if - many or most - women who are considering abortion tend to pursue abortion rather than adoption today, what reason do we have to think this will change when ectogestation becomes a reality?

First, given the additional risks that are posed — however small — there does not seem to be any obvious reason why women who would consider abortion would opt for ectogestation when they so rarely choose to complete gestation (or at least wait until viability) and then give their child up for adoption. In fact, not only are there risks posed by surgery, but presumably there would also be some risk to the foetus from the transfer to the artificial womb, risks that are likely to outweigh those it would be exposed to if the pregnancy was left uninterrupted. Ectogestation, if completed around the time that most abortions are completed, would entail that women with an unintended pregnancy are spared the responsibilities and challenges of an extended period of pregnancy, but if one intends to give one's child up for adoption-for the child's long-term benefit - then why not opt for completing the pregnancy without all of the additional risks? The artificial womb technology being developed is aimed primarily at reducing neonatal mortality caused by premature birth (Partridge et al. 2017) and would likely be utilised by women experiencing a pregnancy that poses a risk to their own health (Romanis et al. 2020). It is not being developed as an alternative to abortion as the technology is not expected to be within the purview of early pregnancy. If ectogestation entails a risk to the mothers' health and an additional risk to the gestatelings' health and adoption is viewed by women considering abortion as psychologically harmful and morally irresponsible, then ectogestation is unlikely to radically transform the problem of abortion.

Second, one must consider the potential social changes that the possibility of ectogestation could bring about. Artificial gestation compared with natural gestation would be visible - gestation becomes observable in a way that was only possible infrequently under ultrasound. This is not beyond the realms of possibility as the Biobag used to gestate lamb foetuses for up to 28 days by Partridge et al. (2017) was transparent and therefore observable throughout the process. Artificial gestation could become something of a spectacle that can be enjoyed by the parent/s, family, friends and the community. It may also have the effect of humanising the subject of ectogestation - the gestateling - and creating increased stigmatisation of induced abortion. It is possible that ectogestation will cause an increase in stigma that could discourage some women from obtaining an abortion. However, given the risks involved with ectogestation outlined above, an increase in stigma towards abortion may lead to an uptake in adoption without the use of ectogestation. Moreover, stigma against abortion already exists (Cárdenas et al. 2018; Biggs et al. 2020), and adoption is already an option. Ectogestation, therefore, would have to create additional stigma to have any real effect on the incidence of induced abortion.

\section{Problems That Must Be Overcome}

The problems I have outlined are not insurmountable. It could be the case that ectogestation can one day start safely from the first trimester of pregnancy; there are 
hundreds of thousands of individuals or couples willing to adopt; foetal transfer surgery turns out to be low risk and without much inconvenience; restrictions to legal abortion are implemented in several countries; and there is both the technological and medical capacities to support hundreds of thousands of gestatelings each year. On balance, I think each of the scenarios I have described is unlikely to materialise to the scale required to radically transform the problem of abortion.

\section{A New Problem: Gestaticide}

A further issue raised by transferring pregnanciesto an artificial womb is that it means creating a new category of killing — gestaticide (Rodger et al. 2020). Gestaticide describes the deliberate killing of the subject of an artificial womb. It has long been the case that some philosophers have argued that infanticide is morally permissible, and arguments that justify infanticide are likely to also apply to the gestateling. As both are independent of the mother, the case for infanticide and gestaticide must be made on grounds other than bodily autonomy. Peter Singer (2011) has argued that because infants lack characteristics such as rationality, autonomy and self-awareness, then killing them cannot be considered the moral equivalent of killing a human that does possess these characteristics. On such accounts the newborn, like the foetus-and gestateling - should not be understood as persons with a corresponding right to life. ${ }^{5}$ Therefore, fewer reasons would be needed to justify killing them compared to an individual who possesses the characteristics necessary to have a right to life. Similar arguments have been put forward by other philosophers such as Michael Tooley (1983), Nicole Hassoun and Uriah Kriegel (2008), and Alberto Giubilini and Francesca Minerva (2013). ${ }^{6}$ So, even if we accept that there is no right to the death of the foetuswhilst in utero - this may only result in a new ethical debate surrounding the permissibility of gestaticide - which will conceptually resemble the ethical debate surrounding the permissibility of infanticide rather than abortion.

\section{Conclusion}

In summary, I have argued that even if ectogestation becomes possible, this is unlikely to transform the abortion debate. Unless the presence of ectogestation is conjoined with significant abortion restrictions, women are unlikely to opt for ectogestation for the same or similar reasons that they rarely opt to give their child up for adoption. Moreover, the additional stigma created by not using ectogestation is unlikely to be significant enough to modify behaviour to the extent required to transform the problem of abortion. Finally, assuming women were to transfer their unintended pregnancies to an artificial womb for ectogestation, this would simply generate debate concerning a new category of killing - gestaticide. Rather than ending the debate around abortion, it

\footnotetext{
${ }^{5}$ For a discussion of moral status and the relevance of birth, see Colgrove (2019); Romanis (2019); and Colgrove (2020).

${ }^{6}$ More recently defended by Räsänen (2016).
} 
may only reorient it to whether-or when - it is permissible to kill humans undergoing artificial gestation.

Open Access This article is licensed under a Creative Commons Attribution 4.0 International License, which permits use, sharing, adaptation, distribution and reproduction in any medium or format, as long as you give appropriate credit to the original author(s) and the source, provide a link to the Creative Commons licence, and indicate if changes were made. The images or other third party material in this article are included in the article's Creative Commons licence, unless indicated otherwise in a credit line to the material. If material is not included in the article's Creative Commons licence and your intended use is not permitted by statutory regulation or exceeds the permitted use, you will need to obtain permission directly from the copyright holder. To view a copy of this licence, visit http://creativecommons.org/licenses/by/4.0/.

\section{References}

Aiken, A. R. A., \& Bloomer, F. (2019). Abortion decriminalised in Northern Ireland. BMJ, 367, 16330. https:// doi.org/10.1136/bmj.16330.

Bearak, J., Popinchalk, A., Ganatra, B., Moller, A.-B., Tunçalp, Ö., Beavin, C., et al. (2020). Unintended pregnancy and abortion by income, region, and the legal status of abortion: estimates from a comprehensive model for 1990-2019. The Lancet Global Health. https://doi.org/10.1016/S2214-109X(20) 30315-6.

Biggs, M. A., Brown, K., \& Foster, D. G. (2020). Perceived abortion stigma and psychological well-being over five years after receiving or being denied an abortion. PLoS One, 15(1), e0226417. https://doi.org/ 10.1371/journal.pone.0226417.

Blackshaw, B. P., \& Rodger, D. (2019). Ectogenesis and the case against the right to the death of the foetus. Bioethics, 33(1), 76-81. https://doi.org/10.1111/bioe.12529.

Blackshaw, B. P., \& Rodger, D. (2020). Questionable benefits and unavoidable personal beliefs: defending conscientious objection for abortion. Journal of Medical Ethics, 46, 178-182. https://doi.org/10.1136/ medethics-2019-105566.

Cannold, L. (1995). Women, ectogenesis and ethical theory. Journal of Applied Philosophy, 12(1), 55-64. https://doi.org/10.1111/j.1468-5930.1995.tb00119.x.

Cárdenas, R., Labandera, A., Baum, S. E., et al. (2018). "It's something that marks you”: abortion stigma after decriminalization in Uruguay. Reproductive Health, 15, 150. https://doi.org/10.1186/s12978-018-0597-1.

Colgrove, N. (2019). Subjects of ectogenesis: are 'gestatelings' fetuses, newborns or neither? Journal of Medical Ethics, 45, 723-726. https://doi.org/10.1136/medethics-2019-105495.

Colgrove, N. (2020). Artificial wombs, birth and 'birth': a response to Romanis. Journal of Medical Ethics, 46, 554-556. https://doi.org/10.1136/medethics-2019-105845.

Finer, L. B., Frohwirth, L. F., Dauphinee, L. A., Singh, S., \& Moore, A. M. (2005). Reasons U.S. women have abortions: quantitative and qualitative perspectives. Perspectives on Sexual and Reproductive Health, 37(3), 110-118. https://doi.org/10.1111/j.1931-2393.2005.tb00045.x.

Giubilini, A., \& Minerva, F. (2013). After-birth abortion: why should the baby live? Journal of Medical Ethics, 39, 261-263. https://doi.org/10.1136/medethics-2011-100411.

Guillaume, A., \& Rossier, C. (2018). Abortion around the world: an overview of legislation, measures, trends, and consequences, transl. P Reeve. Population, 73, 271-306.

Hassoun, N., \& Kriegel, U. (2008). Consciousness and the moral permissibility of infanticide. Journal of Applied Philosophy, 25, 45-55. https://doi.org/10.1111/j.1468-5930.2008.00392.x.

Hendricks, P. (2018). There is no right to the death of the fetus. Bioethics, 32(6), 395-397. https://doi.org/10. 1111/bioe.12455.

Jones, R. K., Frohwirth, L. F., \& Moore, A. M. (2008). "I would want to give my child, like, everything in the world": how issues of motherhood influence women who have abortions. Journal of Family Issues, 29(1), 79-99. https://doi.org/10.1177/0192513X07305753.

Kaczor, C. (2018). Ectogenesis and a right to the death of the prenatal human being: a reply to Räsänen. Bioethics, 32(9), 634-638. https://doi.org/10.1111/bioe.12512.

Mathison, E., \& Davis, J. (2017). Is there a right to the death of the foetus? Bioethics, 31(4), 313-320. https:// doi.org/10.1111/bioe.12331. 
National Institute for Health and Care Excellence. (2019). Abortion before 14 weeks: choosing between medical or surgical abortion Decision aid. https:/www.nice.org.uk/guidance/ng140/resources/abortionbefore-14-weeks-choosing-between-medical-or-surgical-abortion-patient-decision-aid-pdf-6906582255. Accessed 6 Oct 2020.

Partridge, E. A., Davey, M. G., Hornick, M. A., Homick, M., et al. (2017). An extra-uterine system to physiologically support the extreme premature lamb. Nature Communications, 8, 1-15. https://doi.org/10. 1038/ncomms 15112 .

Popinchalk, A., \& Sedgh, G. (2019). Trends in the method and gestational age of abortion in high-income countries. BMJ Sexual \& Reproductive Health, 45, 95-103. https://doi.org/10.1136/bmjsrh-2018-200149.

Räsänen, J. (2016). Pro-life arguments against infanticide and why they are not convincing. Bioethics, 30(9), 656-662. https://doi.org/10.1111/bioe.12281.

Räsänen, J. (2017). Ectogenesis, abortion and a right to the death of the fetus. Bioethics, 31(9), 697-702. https://doi.org/10.1111/bioe.12404.

Rodger, D., Colgrove, N., \& Blackshaw, B. P. (2020). Gestaticide: killing the subject of the artificial womb. Journal of Medical Ethics. http://dx.doi.org/10.1136/medethics-2020-106708

Romanis, E. C. (2018). Artificial womb technology and the frontiers of human reproduction: conceptual differences and potential implications. Journal of Medical Ethics, 44(11), 751-755. https://doi.org/10. 1136/medethics-2018-104910.

Romanis, E. C. (2019). Artificial womb technology and the significance of birth: why gestatelings are not newborns (or fetuses). Journal of Medical Ethics, 45, 728-731. https://doi.org/10.1136/medethics-2019105723.

Romanis, E. C., Begović, D., Brazier, M. R., et al. (2020). Reviewing the womb. Journal of Medical Ethics. https://doi.org/10.1136/medethics-2020-106160.

Sedgh, G., Bearak, J., Singh, S., et al. (2016). Abortion incidence between 1990 and 2014: global, regional, and subregional levels and trends. Lancet, 388, 258-267. https://doi.org/10.1016/S0140-6736(16)303804.

Simonstein, F., \& Mashiach-Eizenberg, M. (2009). The artificial womb: a pilot study considering people's views on the artificial womb and ectogenesis in Israel. Cambridge Quarterly of Healthcare Ethics, 18(1), 87-94. https://doi.org/10.1017/s0963180108090130.

Singer, P. (2011). Practical ethics (3rd ed.). Cambridge: Cambridge University Press.

Sisson, G., Ralph, L., Gould, H., \& Foster, D. G. (2017). Adoption decision making among women seeking abortion. Women's Health Issues, 27(2), 136-144. https://doi.org/10.1016/j.whi.2016.11.007.

Stratman, C. M. (2020). Ectogestation and the problem of abortion. Philosophy and Technology. https://doi. org/10.1007/s13347-020-00427-2.

Tooley, M. (1983). Abortion and infanticide. Oxford: Oxford University Press.

Publisher's Note Springer Nature remains neutral with regard to jurisdictional claims in published maps and institutional affiliations. 